\title{
Tripartite Evolutionary Game Analysis of Trust Relationship between Enterprises in a Cloud Manufacturing Environment: A Service Composition Perspective
}

\author{
Jing Wang $(\mathbb{D}$, Bao Yang $\mathbb{D}$, and Lili Zhai $\mathbb{D}$ \\ School of Economics and Management, Harbin University of Science and Technology, Harbin 150080, China \\ Correspondence should be addressed to Bao Yang; yangbao_1998@163.com
}

Received 26 November 2021; Accepted 3 January 2022; Published 29 January 2022

Academic Editor: Daqing Gong

Copyright (c) 2022 Jing Wang et al. This is an open access article distributed under the Creative Commons Attribution License, which permits unrestricted use, distribution, and reproduction in any medium, provided the original work is properly cited.

\begin{abstract}
Due to the existence of limited rationality and information asymmetry, trust between enterprises in the cloud manufacturing environment is characterized by significant complexity. In this paper, to promote the formation of a better trust relationship between enterprises and to ensure the efficient service and stable operation of the manufacturing process to a greater extent, we take into account the subjective cognition of the game parties from the perspective of service combination, introduce the prospect theory, construct an evolutionary game model of "service demander-service provider-platform supervisor," analyze the evolutionary stabilization strategy, and explore the influence of different factors on the interenterprise trust relationship in the cloud manufacturing environment through numerical simulation. The results show that enhancing the synergy between multiple service providers has a significant impact on improving trust between cloud manufacturing enterprises. The rewards and punishments of the cloud manufacturing platform are conducive to improving interenterprise trust. There exists a critical value dividing opportunistic behavior into explicit and implicit behaviors. When it is less than the critical value, opportunistic behavior is implicit and the service demander trusts the service provider and the transaction continues; when it is greater than the critical value, opportunistic behavior is explicit and the service demander no longer trusts until the service provider is fully trustworthy. The inhibitory effect of good transaction history on opportunistic behavior is evident. Finally, the reasons and effects of the above factors and the subjective perceptions of the game parties in cloud manufacturing are discussed, as well as their concrete manifestations in the CASICloud (China Aerospace Science\&Industry Cloud) and relevant suggestions are put forward.
\end{abstract}

\section{Introduction}

With the development and promotion of the new generation of information technology, the development model of the manufacturing industry has undergone profound changes [1]. Cloud manufacturing is a new model of networked manufacturing [2]. It has more flexibility, mobility, and dynamics than traditional production methods. It virtualizes and services all kinds of manufacturing resources and manufacturing capabilities [3, 4], and carries out multi-party sharing and cooperation through the network platform to provide users with heterogeneous, integrated, on-demand, high security, and expandable manufacturing life cycle services [5].

As manufacturing tasks become increasingly complex, the variety and number of cloud manufacturing services are growing, and the service composition is better able to meet the diverse needs of users. However, it is an increasingly complex task to ensure optimal service quality while meeting the needs of users. One of the reasons for this complexity is that enterprises on cloud manufacturing platforms are distributed in different geographical areas, and the information is scattered. The authenticity, reliability, and integrity of information are not easily guaranteed [6-8], making it difficult for service demanders to find a trusted service provider and obtain the desired service they need. Therefore, the trust problem between enterprises in the cloud manufacturing environment will not only affect service quality and plague service transactions but also slow down the development and application of cloud manufacturing. 
At the moment, cloud manufacturing trust research is primarily focused on evaluation and recommendation. Its findings primarily demonstrate the impact of various service types [9], service requirements [10-12], and service resources [13] on trust. However, there are still a few issues to be resolved. To begin with, existing studies primarily focus on a single cloud manufacturing service, which necessitates a closer examination of the sources and credibility of specific indicators. Second, previous research has overlooked the issue of dynamic changes in cloud manufacturing information.

Compared to a single cloud manufacturing service, cloud manufacturing service composition is the compilation of multiple simple cloud manufacturing services into a complex cloud service [14], which has the characteristics of multiple subjects, nonlinearity, and uncertainty. Studying the interenterprise trust problem in the cloud manufacturing environment from the perspective of service composition can fully consider the interests of each participating subject in cloud manufacturing, as well as the anomalies that occur due to dynamics and instability in the manufacturing service process, improve service quality, effectively enhance the operational efficiency of the cloud manufacturing system, and realize enterprise manufacturing business. Although the evolutionary game approach can dynamically reflect the evolution of enterprises' strategies in the competition process while taking into account differences at the enterprise level and research obstacles caused by incomplete access to information, the traditional evolutionary game model cannot effectively explain irrational psychological factors and risk preference problems of game subjects. Therefore, we combine prospect theory with evolutionary game, using the prospect value function to improve the variables and parameters of the original game, by constructing the evolutionary game model of the service provider, the service demander, and the platform supervisor, and analyzing and solving the evolutionary stabilization strategy in this paper. The impact of factors such as the degree of collaboration among multiple service entities, the platform reward and punishment system, opportunistic behavior, and interaction history on the trust relationship between enterprises in the cloud manufacturing environment are compared and analyzed to discuss the evolution law of the trust relationship between enterprises from multiple dimensions and give relevant suggestions.

The main contributions of this paper are as follows:

(1) The issue of trust between enterprises in cloud manufacturing is studied from the perspective of service composition, the factors affecting trust relationships are systematically analyzed, and suggestions are made to promote trust between enterprises in the cloud manufacturing environment, bridging the gap between the current research conducted mainly from a single cloud manufacturing service.

(2) The preferences and limited rationality of enterprises in the cloud manufacturing environment can be fully considered by introducing prospect theory, and a three-party trust evolution game model for cloud manufacturing service providers, service demanders, and platform supervisors can be constructed based on the service composition perspective, which improves the existing evolution game variables and parameters on the one hand, and extends the research on the other.

(3) China Aerospace Science\&Industry Cloud is used as an application example to demonstrate the efficacy of the proposed theories and suggestions, as well as to provide a reference case for future research.

The rest part of this paper is organized as follows. Section 2 reviews the relevant literature. Section 3 sets out the research problem and puts forward the basic parameters and related assumptions of the theoretical model. Section 4 constructs a tripartite evolutionary game model of cloud manufacturing trust and determines the equilibrium and stable state of the model. Section 5 compares and analyzes the influence of different parameter changes on the evolution results through numerical simulation. Section 6 further discusses the impact of synergy between service entities in the service composition, the emergence and inhibition of opportunistic behavior, and platform rewards and penalties on the trust relationship between cloud manufacturing enterprises, and uses the example of CASICloud to demonstrate this. Section 7 summarizes the paper and puts forward relevant suggestions and deficiencies.

\section{Literature Review}

2.1. Cloud Manufacturing Service Composition. With the application of a new generation of information technology, Li et al. pioneered the concept of "cloud manufacturing" to meet the challenges of sustainable economic and social development and globalization of manufacturing [2, 15]. Many scholars have then conducted a lot of research and exploration of the aspects of theory and framework [16], resource description and encapsulation [17, 18], task scheduling, and resource allocation [19-21]. The cloud manufacturing service is also developed from the concept of "manufacturing as a service." For the study of cloud manufacturing services, scholars mainly involve service evaluation [22, 23], service optimization [24], service matching [25], service composition [26], and other aspects. With the continuous development of cloud manufacturing and the increasing demand of users, service composition has gradually become a research hotspot in the field of cloud manufacturing services. Different scholars have studied optimization frameworks and models for cloud manufacturing service composition [27, 28], service composition evaluation methods [29], and adaptation of service composition [30] from different aspects. Due to the various heterogeneous types of cloud manufacturing resources, the high degree of virtualization of cloud services, the difficulty of guaranteeing service quality, and the complexity of user needs, the research on cloud manufacturing trust related to service composition has gradually attracted the attention of the industry. Li et al. [14] analyzed and studied the reliability 
and credibility of cloud manufacturing services, and a multiobjective optimization model for a combination of cloud manufacturing services has been constructed, taking into account several factors, and conducted a more comprehensive evaluation of the comprehensive performance of the service composition. Wang et al. [31] proposed a hybrid algorithm to solve large-scale service composition optimization problems to improve the service composition optimization rate. However, the above research is limited to static analysis to improve the quality and accuracy of the service selection process and does not take into account the dynamics of cloud manufacturing service composition. The establishment of the trust relationship between enterprises in a cloud manufacturing environment is a continuous and dynamic process between various entities, which is affected by each enterprise's cognition of each other's information and strategy choice. Therefore, evolutionary game theory provides a research method for analyzing the trust relationship between enterprises. The evolutionary game theory can better describe the interaction and dynamic relationship between various entities.

\subsection{Application of Evolutionary Game in Cloud} Manufacturing Research. The evolutionary game theory first appeared in biology [32]. The key premise was that, based on the assumption of bounded rationality, gaming parties would learn and improve their strategies across several games until they found the best one [33]. In existing cloud manufacturing, evolutionary game research is primarily focused on incentives, service configuration, resource sharing, and so on. To increase the operational effectiveness of the supply chain, He et al. [34] established an evolutionary game model of knowledge transfer between cloud manufacturing enterprises and customers. Li et al. [35] proposed a new type of incentive mechanism and studied the acceptance and effectiveness of the mechanism by evolutionary game theory in response to the difficulty of cooperation in the service network and the failure to effectively promote cooperation. Wang et al. [36] developed an evolutionary game model from the perspective of the population to observe manufacturing services with different distribution tendencies and proposed a multi-user-oriented manufacturing service configuration framework to adapt to the decentralized decision-making management practice of manufacturing service distribution. Qi et al. [37] established an evolutionary game model based on the cloud manufacturing resource-sharing model, solved the equilibrium points under the two states of uniform mixing and nonuniform mixing, established an evolutionary game SD Simulation Model of manufacturing resource sharing by using system dynamics, and analyzed the impact of different factors on the final evolution result of cloud manufacturing. $\mathrm{Xu}$ and $\mathrm{Li}$ [38] established an SD model based on system dynamics software and analyzed the impact of different parameter changes on evolution results to resource sharing and collaboration among cloud manufacturing enterprises. The above research used evolutionary game theory to analyze the dynamic behavior of different entities in various situations. The research objective is mainly between cloud manufacturing enterprises, ignoring the role of the cloud platform. In the cloud manufacturing environment, enterprises should establish a good trust relationship. Although it directly depends on the degree of synergy of the enterprises, the history of interaction, and other factors, the role of the cloud manufacturing platform cannot be ignored. The cloud manufacturing platform is responsible for selecting the resources or services that meet users' needs after receiving their requests, overseeing service transactions, providing reward and punishment methods, and providing valueadded services, among other things. Therefore, we need to consider the factor of cloud manufacturing platforms to study the trust relationship between enterprises.

\subsection{Occurrence and Suppression of Opportunistic Behavior in} Cloud Manufacturing. The cloud manufacturing environment is dynamic and open, and it is subject to a variety of uncertainties, including unpredictable service increases and decreases, service failures, and changes in service quality. Some scholars have considered the influence of the history of interactions [39], quality [40], service satisfaction [41], time decay [42], and other factors in cloud manufacturing trust research, effectively controlling the risk of trust caused by dishonesty or malicious falsehood. However, in the cloud manufacturing system, the amount of transactions is often huge and mainly nonfinished product transactions, the quality of the service cannot be evaluated in time, the enterprise information is relatively scattered, and the package of services is not accurate $[43,44]$. Service entities will have opportunistic behaviors such as hiding information, modifying contracts, transferring risks, or evading responsibilities. The existence of opportunistic behavior will result in the loss of efficiency, which is not conducive to the cooperation and transaction of enterprises, and will also hinder the development of cloud manufacturing. To restrain the occurrence of opportunistic behavior, different scholars study it from different angles. Yang et al. [45] reduce the impact of opportunism on the performance of logistics provider alliances through process control. Su [46] found that contract control and trust control can reduce opportunistic behavior in cooperative R\&D. Li et al. [47] believe that long-term cooperation orientation has a check and balance effect on the opportunistic behavior of key suppliers. However, the above research does not consider inhibiting the emergence of opportunistic behavior through its history of interactions. The cloud manufacturing system is still in its early stages, and there is not enough data to make individual assessments or recommend services. Service demanders rely primarily on their experience and minimal information to choose services. They are more likely to believe in themselves and their participatory experience [22]. Therefore, it is very necessary to combine the two and inhibit the occurrence of opportunism through interactive historical factors.

2.4. Prospect Theory. Prospect theory was proposed by Tversky and Kahneman in 1979 based on psychological experiments [48]. It argued that in reality, people cannot 
have complete information and accurately evaluate the utility of all options, so their decision-making behavior was not fully rational and based on utility maximization. User centricity is one of the key features of cloud manufacturing. Users will consider their preferences and personalized needs when selecting services. Therefore, when selecting strategies, the game party is based on the perception of the benefit value of the strategy rather than the objective actual utility. This perceived value is in line with the characteristics of prospect theory. At present, scholars have applied prospect theory to many fields such as environmental pollution [49], decision analysis [50], PPP project governance [51], low carbon economy [52], energy investment [53], etc. In cloud manufacturing, some scholars have used prospect theory to study resource allocation [54], but few have used it to study trust issues. Enterprises in cloud manufacturing hope to obtain the greatest benefits at the lowest cost and the cloud manufacturing platform also intends to attract an increasing number of users, but the rewards to all parties are dependent on how the other roles behave. In the case of asymmetric information, the strategic choices of all stakeholders are not consistent with the expected benefits. Therefore, the combination of "prospect theory" and the evolutionary game makes the enterprises in the cloud manufacturing environment always implement the bounded rationality hypothesis in the whole process of perception and decisionmaking, to get closer to the actual results and further explain the trust relationship between enterprises in the cloud manufacturing environment.

\section{Problem Description and Model Assumptions}

3.1. Problem Description. On the cloud manufacturing platform, there are three main types of entities: service provider, service demander, and platform supervisor. In the service composition, the service provider is composed of multiple service entities. The service provider releases idle manufacturing resources and virtualized services on the cloud manufacturing service platform. These resource services are further organized into cloud services and managed by the platform supervisor. The service demander releases product manufacturing requirements and tasks through the cloud manufacturing service platform. After receiving the needs submitted by users, the platform supervisor will select resources or services that meet the needs from the service platform and feed them back to the users, and be responsible for the daily operation of the platform, supervise the transactions between the two parties, provide rewards and punishments, and provide value-added services.

To improve the trust relationship between enterprises in the cloud manufacturing environment, develop a fair and credible service trading environment, preserve the interests of all parties, and decrease risks, the following considerations must be examined from the perspective of service composition. Firstly, the service composition process involves multiple categories of stakeholders. Each stakeholder group is a separate entity that makes its decisions and has its set of interests [55]. As a result, there may be behavioral decision-making errors. The use of prospect theory can help to represent the subjective perceptions of risks, earnings, and losses among stakeholders. Secondly, cloud manufacturing service composition is an orderly combination according to the user's needs, task processes, and the internal logic of the business, which requires the participation of multiple service entities. The whole process includes a large number of links and steps, making the cooperation mode between multiple service entities unpredictable and unmanageable. The degree of synergy between them will directly affect the service process and indirectly affect users' trust in services. Thirdly, although the main participants in the service composition process are service demanders and service providers, enterprises lack transaction history and adopt a conservative attitude toward transactions. At this time, the role of the cloud manufacturing platform is very important. It not only provides a carrier for cloud manufacturing services but also needs to help enterprises match appropriate partners to ensure the smooth progress of the service. Finally, because the cloud manufacturing platform contains a variety of resources, the service composition generated for user publishing tasks is fuzzy and uncertain. In addition, some service providers may have opportunistic behavior in the service process, which will lead to the inability to establish a good trust relationship between enterprises. The whole process is shown in Figure 1.

\subsection{Model Assumptions}

Assumption 1. The service provider $(S)$, platform supervisor $(G)$, and service demander $(D)$ are the three major entities on the cloud manufacturing platform. In the game process, the three sides are boundedly rational and play several games to identify the best strategy. Individual strategy selection is primarily dependent on subjective psychological feelings about the approach's benefits and losses, rather than the actual value. Use the prospect theory to measure the subject's profit and loss, and define the subject's psychological perception of the value of payment as the prospect value $V$, which is composed of a value function $V(\Delta r)$ and a weight function $\pi(p)$, namely,

$$
\begin{gathered}
V=\sum_{i=1}^{n}\left(\pi\left(p_{i}\right) v\left(\Delta r_{i}\right)\right), \\
v(\Delta r)=\left\{\begin{array}{l}
\Delta r^{n}, \quad \Delta r>0, \\
-\lambda(-\Delta r)^{\eta}, \quad \Delta r<0,
\end{array}\right. \\
\pi(p)=\frac{p^{\gamma}}{\left[p^{\gamma}+(1-p)^{\gamma}\right]^{1 / \gamma}},
\end{gathered}
$$

where $\Delta r_{i}$ represents the difference between the actual payment value of the game player and the value of the reference point after the occurrence of situation $i, p$ represents the probability of occurrence of situation $i$. $\pi\left(p_{i}\right)$ is the decision weight, which is a function of $p_{i}$, and $\pi(0)=0$, 


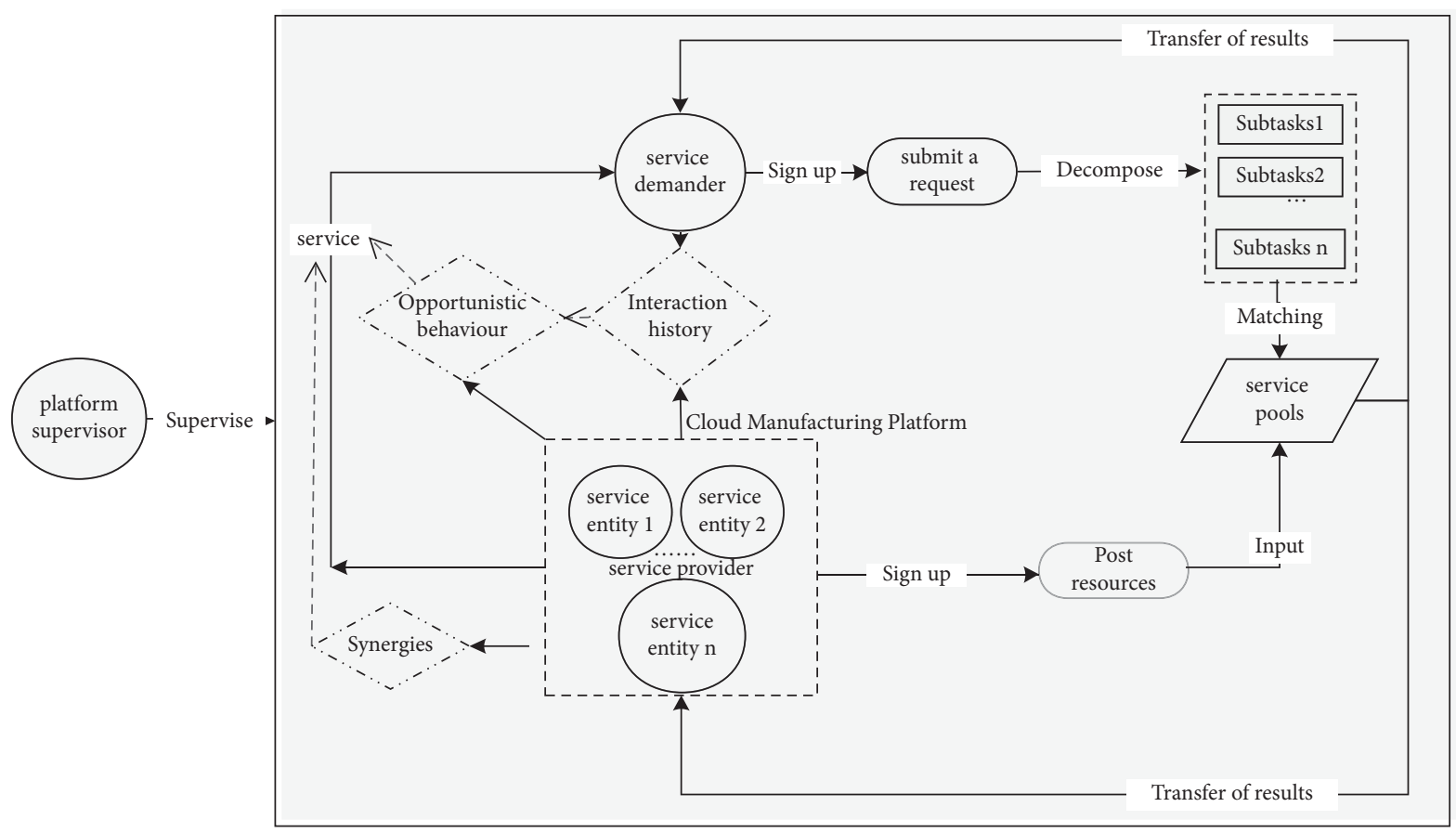

FIGURE 1: Cloud manufacturing service process diagram.

$\pi(1)=1$. The parameter $\eta$ represents the marginal sensitivity of value $(0<\eta<1)$. The larger the $\eta$, the lower the sensitivity of the game subject to value and the riskier it is. When $\eta=1$, it means that the risk is neutral. The parameter $\lambda$ represents the loss avoidance factor $(\lambda>) ; \gamma$ is the weight sensitivity factor; the larger the value of $\lambda$, the larger the value of $\gamma$.

Assumption 2. Trust is crucial in the transaction between the service demander and the service provider on the cloud manufacturing platform. The service demander hopes to find a dependable service provider who can not only meet their immediate needs but also interact with their long-term requirements. The service provider hopes to gain a long-term stable customer, make full use of its excess resources, reduce the phenomenon of insufficient resource utilization, and gain more benefits. In the transaction process, the service provider first signs a contract with the service demander, but a service entity in the service provider may lose trust due to some interests in the service composition. The platform supervisor's purpose in constructing this platform is to serve both parties. It can provide both parties with certification upgrading, fee reduction, and other benefits, and supervise the transaction process of both parties. It can also choose not to offer concessions and not to supervise the transaction process of both parties. The set of strategies is (supervision, nonsupervision). The service demander can directly choose trust or distrust for the counterparty of the transaction, and its selection strategy combination is (trust, distrust). The service provider chooses to be trustworthy or untrustworthy for ongoing transactions. The combination of its selection strategy is (trustworthy, untrustworthy).
Assumption 3. Although the platform supervisor will not be directly involved in the transaction process, it will formulate corresponding incentive and punishment systems for the service provider and the service demander, and supervise the transaction process of the service provider and the service demander, and the total cost incurred is $C$. As the main participant in the transaction process, the service provider will inevitably invest a certain amount of manpower, material, and financial resources. The total cost incurred by the service provider when adopting a trustworthy strategy is $C_{1}$. The cost incurred by the service provider when adopting the untrustworthy strategy is $C_{4}$ $\left(C_{4}<C_{1}\right)$. The cost of information collection and other costs paid by the service demander is $C_{2}$. If the service demander adopts a distrust strategy, the transaction will not be concluded. When the service demander places trust in the service provider and the service provider betrays that trust by acting opportunistically, the service demander suffers a perceived loss qC3, where $\mathrm{q}$ is the presence or absence of a positive history of contact between the parties. The range of $q$ is $0-1$, and a trend toward 0 indicates that the two parties have a better history of interaction. Trending to 1 means that the two parties have no history of interaction, or the number of interactions is small, and further communication is needed. Due to the untrustworthiness of the service provider, the trust of the service demander in the platform is reduced, adding perceived loss to $C_{5}$.

Assumption 4. $R_{1}$ is used to represent the income obtained by the platform supervisor when choosing the "supervision" strategy, and $b$ represents the percentage of the income obtained by the platform supervisor from choosing the 
"nonsupervision" strategy to the proportion of the income obtained by the platform supervisor choosing the "supervision" strategy, then the platform supervisor chooses the "nonsupervision" strategy to obtain the benefit $b R_{1}$, and the value range of $b$ is between 0 and 1 . Let $R_{2}$ represent the transaction price of cooperation between the service provider and the service demander. When the service demander chooses to trust the other party and the service provider chooses to be trustworthy, the degree of mutual trust is increased and the transaction is completed perfectly, which will promote communication and cooperation between the two parties, and will bring additional perceived benefits to the service provider and the service demander $R_{3}$, the coefficient of the sharing ratio of this part of the income is $a$, so that the income obtained by the service provider is $a \alpha R_{3}, \alpha$ represents the degree of synergy between multiple service entities in the service Composition and the range of $\alpha$ is $0-1$, the greater the value of a, the better the degree of synergy. The revenue obtained by the service demander is $(1-a) R_{3}$. In addition, the platform supervisor provides certification rights support to the two parties that actively participate in the interaction. Specific certification rights support includes performance information, quality certification, and credit certification. The service provider can obtain discounts such as online business promotions, and thus obtain additional perceived benefits $G_{1}$. Service demanders can obtain valueadded service reductions, exclusive offline services, and so on and thus obtain perceived additional benefits $G_{2}$. When the service demander adopts trust and the service provider losses its trust, the service provider losses its trust due to opportunistic behavior, which will bring additional perceived benefits $q \alpha R_{4}$. However, all of the above benefits are based on the transaction between the two parties.

Assumption 5. In the context of cloud manufacturing services, the agreement management in the SLA (service level agreement) management mechanism also has the content of enterprise contract management, which is systematic and dynamic management facing the entire operation of the manufacturing service provider. The purpose is to avoid being untrustworthy in the transaction process between the service provider and the service demander under the supervision of the platform supervisor. And, when the service demander chooses to carry out trust and the service provider breaks trust due to opportunistic behavior, the service provider is required to pay a penalty to the service demander, denoted as $K$. When the platform supervisor supervises, it will also impose additional perceptual penalties on the service provider for untrustworthy behavior, denoted as $W$.

Assumption 6. In the model, the service demander, service provider, and platform supervisor make relevant policy choices. Assuming that the probability of the service demander choosing to trust is $X(0 \leq X \leq 1)$, then the probability of choosing distrust is $X(0 \leq X \leq 1)$ is $1-X$. The probability that the service provider chooses to be trustworthy is $Y(0 \leq Y \leq 1)$, then the probability that the service provider chooses to be untrustworthy is $1-Y$. The probability that the platform supervisor chooses supervision is $Z(0 \leq Z \leq 1)$, the probability of choosing not to supervise is $1-Z$.

In summary, the symbolic assumptions are shown in Table 1.

Based on the above assumptions, a bounded rational tripartite game model is constructed, and the game benefit perception matrix is shown in Table 2 .

From the prospect theory, it can be known that the benefits and costs of the platform supervisor's supervision of the transaction process are deterministic benefits and costs. When the service provider is untrustworthy, it needs to pay a certain penalty to the service demander. Only the service provider and service demander are related to the content of the agreement. The expenditure and income determined are the transaction price for the cooperation between the service provider and the service demander. The cost of human, material, and financial resources invested by the service provider, as well as the cost of information collection invested by the service demander, are deterministic expenditures when the service provider adopts the trust and distrust strategy. Moreover, the degree of synergy $\alpha$ between numerous service subjects under the service composition is unaffected by perceived characteristics. Therefore, $C, C_{1}, C_{2}$, $C_{4}, K, R_{2}$ have no perceptual deviation, while $C_{3}, C_{5}, R_{3}, R_{4}$, $G_{1}, G_{2}, W$ have uncertainty, and all have perceptual characteristics.

(1) When the service demander, service provider, and platform supervisor adopt strategies (trust, trustworthy, supervision), respectively, the probability of trustworthiness is $P_{1}=1$ for the service provider at this time. According to Assumption 4:

$$
\begin{aligned}
G_{1} & =\pi\left(P_{1}\right) v\left(G_{1}\right)+\pi\left(1-p_{1}\right) v\left(G_{1}\right) \\
& =\pi(1) v\left(G_{1}\right)+\pi(0) v\left(G_{1}\right) .
\end{aligned}
$$

Due to $\pi(0)=0, \pi(1)=1$ inferred $G_{1}=v\left(G_{1}\right)$, among them, $G_{1}$ is the reward received by the service provider. In the same way, then

$$
\begin{aligned}
G_{2} & =\pi\left(P_{1}\right) v\left(G_{2}\right)+\pi(0) v(0) \\
& =v\left(G_{2}\right), \\
a \alpha R_{3} & =\alpha \pi(1) v\left(a R_{3}\right)+\pi(0) v(0) \\
& =\alpha v\left(a R_{3}\right), \\
(1-a) R_{3} & =\pi(1) v\left((1-a) R_{3}\right)+\pi(0) v(0) \\
& =v\left((1-a) R_{3}\right) .
\end{aligned}
$$

(2) When the service demander, service provider, and platform supervisor adopt strategies (trust, untrustworthy, supervision), respectively, the probability of untrustworthy is $P_{2}=1$ for the service provider at this time. According to Assumptions $3,-5$, we can see:

$$
\begin{aligned}
W & =\pi\left(P_{2}\right) v(W)+\pi\left(1-P_{2}\right) v(W) \\
& =\pi(1) v(W)+\pi(0) v(W) .
\end{aligned}
$$


TABLE 1: Tripartite evolutionary game model parameters of service demander, service provider, and platform supervisor.

\begin{tabular}{|c|c|}
\hline Parameters & Explanations \\
\hline C & Costs incurred when regulated by the platform supervisor \\
\hline$C_{1}$ & Total costs incurred by the service provider in adopting a trustworthy strategy \\
\hline$C_{2}$ & Total cost to the demand side of the service \\
\hline$C_{3}$ & $\begin{array}{l}\text { When the demand side of the service takes trust, the service provider takes untrustworthy, and the platform regulator does not } \\
\text { regulate, the provider takes opportunism, causing a perceived loss to the demand side }\end{array}$ \\
\hline$C_{4}$ & Disguise costs incurred by the service provider in adopting an untrustworthy strategy \\
\hline$C_{5}$ & The platform supervisor will incur additional perceived losses to itself as a result of the service provider's untrustworthy nature \\
\hline$G_{1}$ & The platform rewards additional service providers for perceived benefits \\
\hline Q & History of service interactions \\
\hline$W$ & $\begin{array}{l}\text { The supervising platform supervisor also imposes additional perceived penalties on the service provider for noncompliance } \\
\text { when the service provider acts in breach of trust }\end{array}$ \\
\hline$R_{1}$ & Benefits received by the platform supervisor when choosing a supervision strategy \\
\hline$R_{2}$ & Transaction prices for cooperation between service providers and service demanders \\
\hline$R_{3}$ & Additional perceived benefits from mutual trust \\
\hline$R_{4}$ & $\begin{array}{l}\text { Additional perceived benefits are received when the service demand side takes trust, the service provider acts untrustworthy, } \\
\text { and the service provider acts opportunistically when the platform supervisor does not supervise }\end{array}$ \\
\hline A & Share of additional benefits R3 to service providers and service demanders \\
\hline$B$ & $\begin{array}{c}\text { Revenue earned by the platform supervisor for the "nonsupervision" strategy as a percentage of revenue earned by the } \\
\text { platform supervisor for the "supervision" strategy }\end{array}$ \\
\hline$G_{2}$ & Platform rewards additional service demand-side perceived benefits \\
\hline$K$ & $\begin{array}{l}\text { When the service demander chooses to trust and the service provider chooses to be untrustworthy, that is, the service provider } \\
\text { defaults, the service provider needs to pay a certain penalty to the service demander }\end{array}$ \\
\hline$\alpha$ & Degree of synergy between multiple service entities \\
\hline
\end{tabular}

TABle 2: Perceived benefits matrix of the evolutionary game between the service demander, service provider, and platform supervisor.

\begin{tabular}{|c|c|c|c|c|c|}
\hline \multirow{2}{*}{\multicolumn{2}{|c|}{$\begin{array}{l}\text { Platform supervisor strategy } \\
\text { Service demander strategy }\end{array}$}} & \multicolumn{2}{|c|}{ Supervision $(z)$} & \multicolumn{2}{|c|}{ Nonsupervision $(1-z)$} \\
\hline & & Trust $(x)$ & Distrust $(1-x)$ & Trust $(x)$ & Distrust $(1-x)$ \\
\hline Service provider strategy & Untrustworthy $(1-y)$ & $\begin{array}{c}G_{1}+a \alpha R_{3}+R_{2}-C_{1} \\
G_{2}+(1-a) R_{3}-R_{2}-C_{2} \\
R_{1}-C \\
q \alpha R_{4}+R_{2}-C_{4}-K-W \\
K+G_{2}-R_{2}-C_{2}-q C_{3} \\
R_{1}-C-C_{5}\end{array}$ & $\begin{array}{l}0 \\
-C_{2} \\
-C \\
-C_{4} \\
-C_{2} \\
-C \\
\end{array}$ & $\begin{array}{c}G_{1}+a \alpha R_{3}+R_{2}-C_{1} \\
G_{2}+(1-a) R_{3}-R_{2}-C_{2} \\
b R 1 \\
q \alpha R_{4}+R_{2}-C_{4}-K \\
K+G_{2}-R_{2}-C_{2}-q C_{3} \\
b R_{1}-C_{5}\end{array}$ & $\begin{array}{c}0 \\
-C_{2} \\
0 \\
-C_{4} \\
-C_{2} \\
0 \\
\end{array}$ \\
\hline
\end{tabular}

${ }^{1}$ The first to third rows in the revenue perception matrix are provider, demander, and platform revenue, respectively. It should be noted that no transaction will occur when the demander chooses not to trust, but some participants have also paid the cost, so it must be included.

Due to $\pi(0)=0, \pi(1)=1$ inferred $W=v(W)$, where $W$ is the reward received by the service provider. In the same way, then

$$
\begin{aligned}
q R_{4} & =\alpha \pi(1) v\left(q R_{4}\right)+\pi(0) v(0) \\
& =\alpha v\left(q R_{4}\right) \\
C_{5} & =\pi(1) v\left(C_{5}\right)+\pi(0) v(0) \\
& =v\left(C_{5}\right) \\
q C_{3} & =\pi(1) v\left(q C_{3}\right)+\pi(0) v(0) \\
& =v\left(q C_{3}\right)
\end{aligned}
$$

\section{Evolutionary Game Model Solution and Analysis}

4.1. Model Solution. The actions of the platform supervisor (G), service provider (S), and service demander (D) interact and influence each other, and constantly adjust the choice of strategy to maximize the benefits. The following is the establishment of a tripartite evolutionary game to copy the dynamic equations to solve the formation conditions and process of the evolutionarily stable strategy.

According to the benefit perception matrix of the tripartite game in Table 2, the available benefit when the service demander chooses trust is

$$
\begin{aligned}
E_{d 1}= & z y\left(G_{2}+(1-a) R_{3}-R_{2}-C_{2}\right)+z(1-y)\left(K+G_{2}-R_{2}-C_{2}-q C_{3}\right) \\
& +y(1-z)\left(G_{2}+(1-a) R_{3}-R_{2}-C_{2}\right)+(1-y)(1-z)\left(K+G_{2}-R_{2}-C_{2}-q C_{3}\right) \\
= & -\left(R_{2}+C_{2}\right)+(1-a) y R_{3}+K+G_{2}+(y-1) q C_{3}-y k .
\end{aligned}
$$


The benefits when the service demander chooses to distrust are

$$
\begin{aligned}
E_{d 2}= & z y\left(-C_{2}\right)+z(1-y)\left(-C_{2}\right) \\
& +y(1-z)\left(-C_{2}\right)+(1-y)(1-z)\left(-C_{2}\right) \\
= & -C_{2} .
\end{aligned}
$$

The average revenue of the service demand side is

$$
\bar{E}_{d}=X E_{d 1}+(1-X) E_{d 2} .
$$

From this, the replication dynamic equation of the service demander can be obtained as follows:

$$
\begin{aligned}
F(x) & =\frac{\mathrm{d} x}{\mathrm{~d} t} \\
& =x\left(E_{d 1}-\bar{E}_{d}\right) \\
& =x(1-x)\left(E_{d 1}-E_{d 2}\right) \\
& =x(1-x)\left[-R_{2}+(1-a) y R_{3}+K+G_{2}+(y-1) q C_{3}-y k\right] .
\end{aligned}
$$

In the same way, the available service provider's benefits when choosing to keep trustworthy are

$$
\begin{aligned}
E_{s 1}= & x z\left(G_{1}+a \alpha R_{3}+R_{2}-C_{1}\right) \\
& +x(1-z)\left(G_{1}+a \alpha R_{3}+R_{2}-C_{1}\right) \\
= & x G_{1}+a \alpha x R_{3}+x R_{2}-x C_{1} .
\end{aligned}
$$

$$
\begin{aligned}
E_{s 2}= & x z\left(q \alpha R_{4}+R_{2}-C_{4}-K-W\right)+z(1-x)\left(-C_{4}\right) \\
& +x(1-z)\left(q \alpha R_{4}+R_{2}-C_{4}-K\right)+(1-z)(1-x)\left(-C_{4}\right) \\
= & -x z W+x q \alpha R_{4}+x R_{2}-x K-C_{4} .
\end{aligned}
$$

The average revenue of service providers is

$$
\bar{E}_{s}=X E_{s 1}+(1-X) E_{s 2} \text {. }
$$

From this, the dynamic equation for replication of the service provider can be obtained as

$$
\begin{aligned}
F(y) & =\frac{\mathrm{d} y}{\mathrm{~d} t} \\
& =y\left(E_{s 1}-\bar{E}_{S}\right) \\
& =y(1-y)\left(E_{s 1}-E_{s 2}\right) \\
& =y(1-y)\left[x G_{1}+a \alpha x R_{3}+x z W-x q \alpha R_{4}+x K+C_{4}-x C_{1}\right] .
\end{aligned}
$$

In the same way, the benefits of the platform supervisor when they choose supervision are

$$
\begin{aligned}
E_{g 1}= & x y\left(R_{1}-C\right)+y(1-x)(-C) \\
& +x(1-y)\left(R_{1}-C-C_{5}\right)+(1-x)(1-y)(-C) \\
= & x R_{1}-x C_{5}+x y C_{5}-C .
\end{aligned}
$$


The benefits when the platform supervisor chooses not to supervise are

$$
\begin{aligned}
E_{g 2} & =x y\left(b R_{1}\right)+x(1-y)\left(b R_{1}-C_{5}\right) \\
& =x b R_{1}-x C_{5}+x y C_{5} .
\end{aligned}
$$

The average income of platform supervisor is

$$
\bar{E}_{g}=X E_{g 1}+(1-X) E_{g 2} .
$$

From this, the dynamic equation for replication of the service provider can be obtained as

$$
\begin{aligned}
F(z) & =\frac{\mathrm{d} z}{\mathrm{~d} t} \\
& =z\left(E_{g 1}-\bar{E}_{g}\right) \\
& =z(1-z)\left(E_{g 1}-E_{g 2}\right) \\
& =z(1-z)\left[x R_{1}-C-x b R_{1}\right]
\end{aligned}
$$

Construct the Jacobian matrix as follows:

$$
\left[\begin{array}{ccc}
(1-2 x)\left[-R_{2}+K+(1-a) y R_{3}+G_{2}+(y-1) q C_{3}-y K\right] & x(1-x)\left[q C_{3}+(1-a) R_{3}-K\right] & 0 \\
y(1-y)\left[G_{1}+K+a \alpha R_{3}+z W-q \alpha R_{4}-C_{1}\right] & (1-2 y)\left[x G_{1}+K x+a \alpha R_{3}+x z W+C_{4}-x q \alpha R_{4}-x C_{1}\right] & y(1-y)[x W] \\
z(1-z)\left[R_{1}-b R_{1}\right] & 0 & (1-2 z)\left[x R_{1}-C-x R_{1}\right]
\end{array}\right]
$$

4.2. Equilibrium Point Analysis. Let $F(x)=F(y)=F(z)=0$, we can get the local equilibrium points $E_{1}(0,0,0), E_{2}(0,0,1)$, $E_{3}(0,1,0), \quad E_{4}(0,1,1), \quad E_{5}(1,0,0), \quad E_{6}(1,0,1), \quad E_{7}(1,1,0)$, and $E_{8}(1,1,1)$. According to the evolutionary game theory, the equilibrium point that satisfies all the eigenvalues of the Jacobian matrix is nontiming and is the ESS (evolutionary stable strategy) of the system. Then, obtain the system equilibrium point and Eigenvalues, as shown in Table 3.

For ease of analysis and no loss of generality, assume that $(1-b) R_{1}-C>0, \quad G_{1}+a \alpha R_{3}+K+W+C_{4}-C_{1} \quad-q \alpha R_{4}>0$, $(1-a) R_{3}+G_{2}-R_{2}>0$, the net benefits of mutual trust between the platform supervisor, the service provider, and service demander are greater than the net benefits from distrust. The following needs to be divided into two situations to start the discussion, as shown in Table 4.

(1) $K+G_{2}-q C_{3}-R_{2}>0$. The sum of the penalty that the service provider needs to pay to the service demander and the additional revenue of the platform that rewards the additional service demander is greater than the sum of the additional cost of the service demander and the transaction price.

In this case, no matter whether the value of $G_{1}+a \alpha R_{3}+K+C_{4}-C_{1}-q \alpha R_{4}$ is positive or negative, that is, when the service provider's income is greater than or less than the return of trustworthiness, the equilibrium point of the system is only one $E_{8}(1,1,1)$, that is, the eigenvalues of the Jacobian matrix corresponding to the equilibrium point $E_{8}(1,1,1)$ are all nonpositive. In this case, the system has only one stable point, and the corresponding evolution strategy is (trust, trustworthy, supervision).

(2) $K+G_{2}-q C_{3}-R_{2}<0$. The total of the penalty that the service provider must pay to the service demander and the additional benefit that the platform provides to the service demander are less than the total of the service demander's increased cost and the transaction price.
In this case, no matter whether the value of $G_{1}+a \alpha R_{3}+K+C_{4}-C_{1}-q R_{4}$ is positive or negative, that is, when the service provider's return on trustworthiness is greater or less than the return on trustworthiness, the equilibrium point of the system is only one $E_{8}(1,1,1)$, that is, the eigenvalues of the Jacobian matrix corresponding to the equilibrium point $E_{8}(1,1,1)$ are all nonpositive. In this case, the system has only one stable point, and the corresponding evolution strategy is (trust, trustworthy, supervision).

\section{Simulation Analysis}

From the perspective of service composition, to better describe the impact of each parameter variable in the revenue perception matrix on the trust relationship between enterprises in the cloud manufacturing environment, this paper simulates the dynamic process of strategy selection of service provider, service demander, and platform supervisor under the condition of stable point, and performs a quantitative analysis of the degree of synergy among multiple service entities, the platform reward and punishment system, opportunistic behavior, and the history of interactions among multiple service entities using MATLAB for numerical simulation and the actual background of cloud manufacturing. Assuming that the $\mathrm{R} 1$ revenue of the platform supervisor's supervision is $\mathrm{R} 1=30$, the cost of the platform supervisor's supervision is $\mathrm{C}=10$, the transaction price is $\mathrm{R} 2=100$, the platform supervisor's nonmonitoring revenue accounts for the proportion of the platform supervisor's choice of supervision revenue $b=0.5$, the cost paid by the service demander is $\mathrm{C} 2=40$, the cost of $\mathrm{C} 1=30$ when the service provider chooses the trustworthy strategy, the cost $C 4=10$, when the untrustworthy strategy is selected. The degree of synergy among multiple service entities is $\alpha=0.5$. The service provider adopts opportunistic behavior, and the additional benefit $R_{4}=70$ is required to pay a certain penalty to the service demander $K=20$, and the penalty $W=10$ from the platform supervisor, so that the additional cost incurred by the service demander is $C_{3}=70$, which 
TABle 3: System Equilibrium points and Eigenvalues.

\begin{tabular}{lccc}
\hline \multirow{2}{*}{ Equilibrium points } & \multicolumn{3}{c}{ Eigenvalues; $x$ : service demander, $y:$ service provider, $z$ : platform supervisor } \\
& $\lambda_{1}$ & $\lambda_{2}$ & $\lambda_{3}$ \\
\hline$E_{1}(0,0,0)$ & $K+G_{2}-q C_{3}-R_{2}$ & $C_{4}$ & $-C$ \\
$E_{2}(0,0,1)$ & $K+G_{2}-q C_{3}-R_{2}$ & $C_{4}$ & $C$ \\
$E_{3}(0,1,0)$ & $(1-a) R_{3}+G_{2}-R_{2}$ & $-C_{4}$ & $-C$ \\
$E_{4}(0,1,1)$ & $(1-a) R_{3}+G_{2}-R_{2}$ & $-C_{4}$ & $C$ \\
$E_{5}(1,0,0)$ & $-\left[K+G_{2}-q C_{3}-R_{2}\right]$ & $G_{1}+a \alpha R_{3}+K+C_{4}-C_{1}-q \alpha \mathrm{r}_{4}$ & $(1-b) R_{1}-C$ \\
$E_{6}(1,0,1)$ & $-\left[K+G_{2}-q C_{3}-R_{2}\right]$ & $G_{1}+a \alpha R_{3}+K+W+C_{4}-C_{1}-q \alpha R_{4}$ & $-\left[(1-b) R_{1}-C\right]$ \\
$E_{7}(1,1,0)$ & $-\left[(1-a) R_{3}+G_{2}-R_{2}\right]$ & $-\left[G_{1}+a \alpha R_{3}+K+C_{4}-C_{1}-q \alpha R_{4}\right]$ & $(1-b) R_{1}-C$ \\
$E_{8}(1,1,1)$ & $-\left[(1-a) R_{3}+G_{2}-R_{2}\right]$ & $-\left[G_{1}+a \alpha R_{3}+K+W+C_{4}-C_{1}-q \alpha R_{4}\right]$ & $-\left[(1-b) R_{1}-C\right]$ \\
\hline
\end{tabular}

TABle 4: Equilibrium points and Situation.

\begin{tabular}{|c|c|c|c|c|c|c|c|c|}
\hline \multirow{2}{*}{ Equilibrium points } & \multicolumn{4}{|c|}{ Situation 1} & \multicolumn{4}{|c|}{ Situation 2} \\
\hline & $\lambda_{1}$ & $\lambda_{2}$ & $\lambda_{3}$ & Stability & $\lambda_{1}$ & $\lambda_{2}$ & $\lambda_{3}$ & Stability \\
\hline$E_{1}(0,0,0)$ & + & + & - & Unstable & - & + & - & Unstable \\
\hline$E_{2}(0,0,1)$ & + & + & + & Unstable & - & + & + & Unstable \\
\hline$E_{3}(0,1,0)$ & + & - & - & Unstable & + & - & - & Unstable \\
\hline$E_{4}(0,1,1)$ & + & - & + & Unstable & + & - & + & Unstable \\
\hline$E_{5}(1,0,0)$ & - &,+- & + & Unstable & + &,+- & + & Unstable \\
\hline$E_{6}(1,0,1)$ & - & + & - & Unstable & + & + & - & Unstable \\
\hline$E_{7}(1,1,0)$ & - &,+- & + & Unstable & - &,+- & + & Unstable \\
\hline$E_{8}(1,1,1)$ & - & - & - & ESS & - & - & - & ESS \\
\hline
\end{tabular}

makes the platform supervisor receive an additional loss $C_{5}=20$, if the two parties have a good interaction history coefficient $q=0.5 ; R 3=240$ is the additional benefit provided by mutual trust, and the sharing ratio is $a=0.5$; the platform supervisor rewards the additional benefits of providers and service demanders $G_{1}=G_{2}=70$. According to the research of Kahneman and Tversky [56], the marginal sensitivity $\eta$ in the value function of the prospect theory is taken as 0.88 , and the loss avoidance coefficient $\lambda$ is taken as 2.25 . Refer to similar literature [57] and take the value of $\gamma$ as 0.61 . And, the initial willingness of the service demander, service provider, and platform supervisor to participate $x=y=z=0.5$.

5.1. The Influence of the Degree of Synergy among Multiple Service Entities on the Trust Relationship. Figure 2 is a simulation of the impact of changes in the degree of synergy among multiple service entities of $\alpha$ on system evolution under the condition that other parameters remain unchanged. As can be seen from the figure, the equilibrium point finally tends to $(1,1,1)$. With the increase of $\alpha$, the convergence speed of $x$ and $y$ accelerates, and the change range of the convergence speed of the service demander is significantly higher than that of the service provider.

The simulation results show that the degree of synergy can affect the trust relationship between enterprises. When there is a good degree of synergy between multiple service entities, it shows that they cooperate efficiently for the manufacturing process to run efficiently and stably, and the service quality can be guaranteed, which increases the trust of the service demander in the service provider and makes the service complete successfully.
5.2. The Impact of Platform Rewards and Punishments on Trust Relationships. Figure 3 is a simulation of the impact of $G_{1}$ changes on the final transaction between the service provider and the service demander when the platform gives the service provider additional rewards under the condition that other parameters remain unchanged. It can be seen from Figure 3 that the equilibrium point eventually tends to $(1,1,1)$. With the increase of $G_{1}$, the convergence speed of $x$ accelerates, so the convergence speed of $y$ and $z$ also accelerates.

Figure 4 is a simulation of the impact of $G_{2}$ changes on the transaction between the service provider and the service demander when other parameters remain unchanged. It can be seen from Figure 4 that the equilibrium point eventually tends to $(1,1,1)$. With the increase of $G_{2}$, the convergence speed of $y$ and $z$ accelerates, and the convergence speed of $x$ does not change significantly.

The simulation results show that the additional rewards of the platform will have a great impact on the service provider and service demander. Providing rewards to service providers will make the service providers more trustworthy and thus increase the trust of the service demanders. Providing rewards to the service demander will also increase the trust of the service demander in the service provider. The platform supervisor in the two figures will also be affected because the benefits of the platform supervisor's supervision are greater than the benefits of nonsupervision.

Figure 5 is a simulation of the impact of changes in the penalty $W$ given to the service provider by the platform to the transaction between the service provider and the service demander when the service provider adopts an opportunistic behavior under the condition that other parameters remain unchanged. It can be seen from the figure that the 


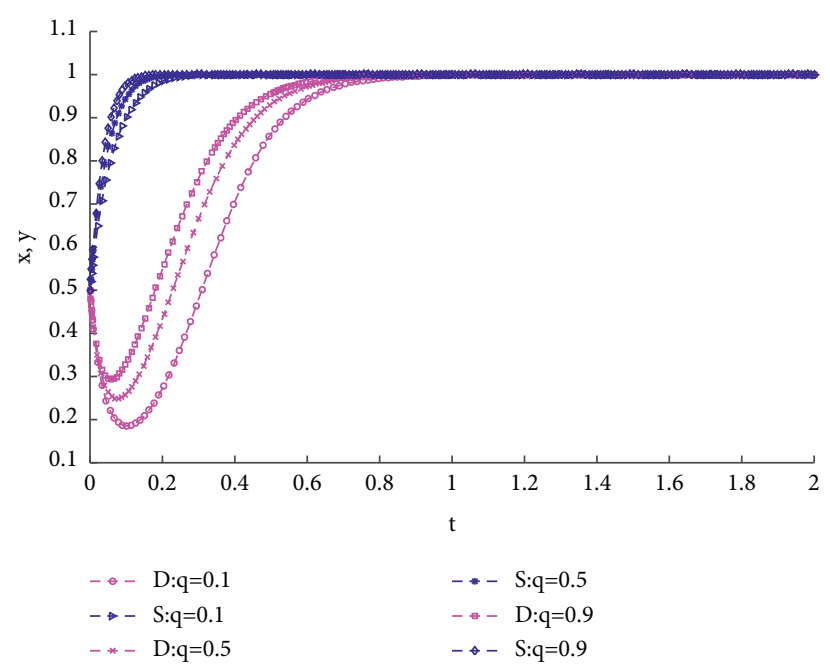

Figure 2: Evolutionary results of changes in synergy among multiple service entities.

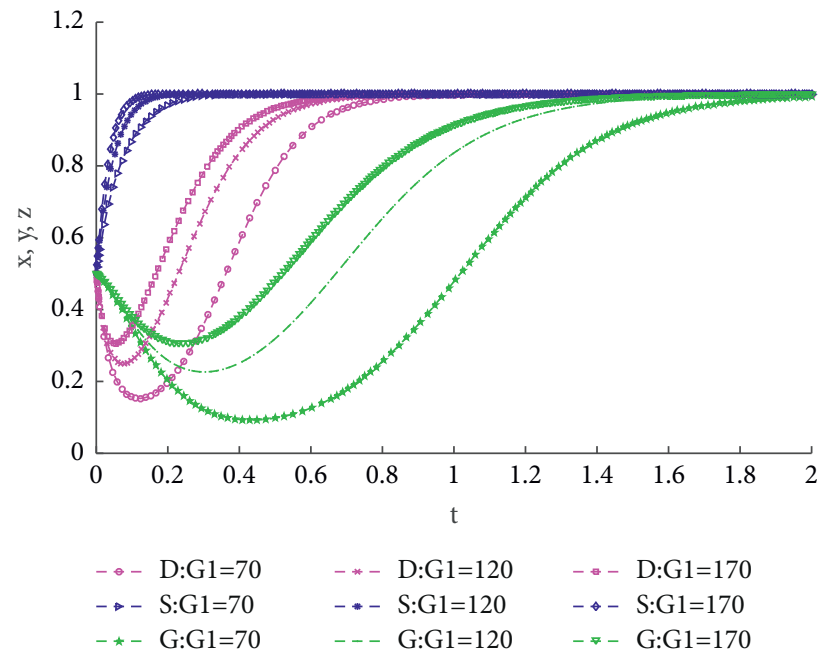

FIGURE 3: The evolutionary result of the platform's rewards for service providers.

equilibrium point eventually tends to $(1,1,1)$. With the increase of $W$, the convergence speed of $y$ increases, which will also cause the convergence speed of $x$ and $z$ to increase.

The simulation results show that when the service provider adopts opportunism, the punishment received by the platform will affect its strategy choice. The increase of punishment can make the service provider more inclined to adopt trustworthy strategies and promote the smooth completion of the transaction.

5.3. The Influence of Opportunistic Behavior and History of Interactions on a Trust Relationship. Figure 6 is a simulation of the impact of changes in $C_{3}$ on the transaction between the service provider and the service demander when the service provider engages in opportunistic behavior in order to cause more losses to the service demander while all other parameters remain constant. The figure shows that the degree of change of $x$ is considerable, and increasing $C_{3}$ will slow down the convergence pace of $x$, but the equilibrium point will eventually gravitate to $(1,1,1)$. When $C_{3}$ is $560, x$ tends to 0 first, and then when $y$ entirely tends to $1, x$ tends to 1 .

Figure 7 is a simulation of the impact of changes in $R_{4}$ on the completion of transactions between the service provider and the service demander when other parameters remain unchanged. It can be seen from the figure that the critical value of $R_{4}$ is around 560. When the value of $R_{4}$ is less than the critical value, the equilibrium point eventually tends to $(1,1,1)$. With the increase of $R_{4}$, the convergence speed of $y$ slows down. The convergence speed of $x$ will also slow down. When $R_{4}$ is larger than the critical value, $x, y$ alternately rises and falls, with $x$ varying as $y$ changes.

The simulation results show that the service provider's opportunistic behavior will increase the additional cost of the service demander or increase the additional revenue it brings to itself, which will affect the degree of the transaction between the two parties. As the additional costs or benefits 


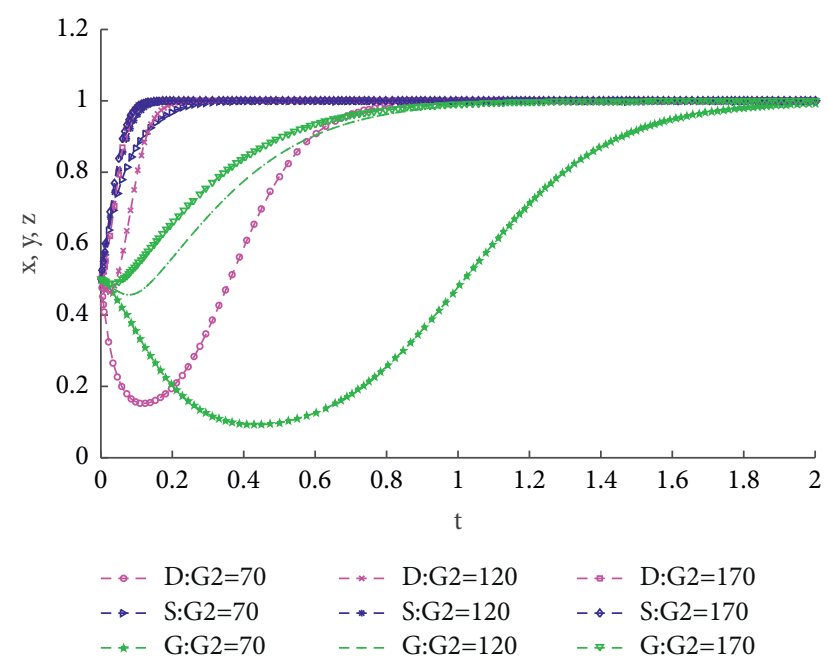

FIgURE 4: The platform rewards the service demander with the evolutionary result of the change.

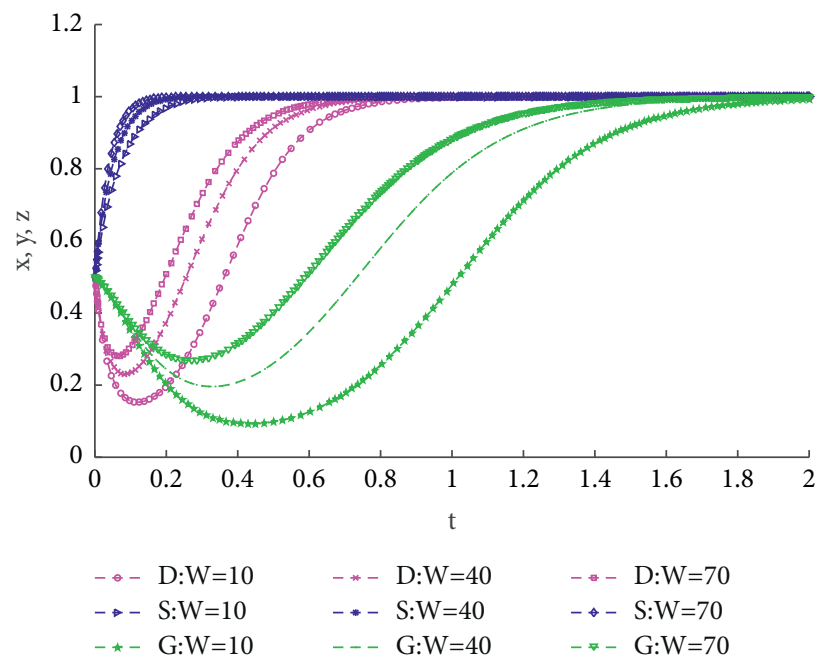

FIgURE 5: The platform penalizes the service provider for the evolutionary result of the change.

increase, the trust of the service demander is also declining. However, due to the particularity of cloud manufacturing, the service demander cannot detect this loss in time. As a result, the service provider will increasingly want to adopt speculative fraud because the behavior of the service provider cannot be discovered in time by the service demander, so the transaction continues without touching the ultimate interest. However, when it reaches a certain level, the service demand will be easily discovered, so it can object to the service provider so that the service provider has to abide by the original agreement to ensure the quality of the service.

Figure 8 shows the influence of the history of interactions coefficient $q$ on the simulation results under the premise that other parameters held constant. It can be seen from Figure 8 that the less the $q$ decreases, the faster the tripartite convergence speed, and the final equilibrium point tends to $(1,1,1)$.

This simulation result shows that a good interaction history can enable the supply and demand parties to reach a transaction faster, and speculation and fraud are not easy to occur in the transaction process so that the transaction can be successfully concluded.

\section{Discussion}

According to the simulation results, the importance of the degree of coordination between the service entities, the specific rewards and punishments of the cloud manufacturing platform, the reasons and results of the differences in opportunistic behaviors, the suppression of opportunistic behaviors by interactive history, and the reasons for the subjective perception of the parties are discussed. Take the CASICloud as an example. The reason for focusing on the CASICloud is that it is one of the representative industrial Internet platforms in China, committed to promoting digitalization, intelligence, and cloudification. Helping manufacturing enterprises to transform and upgrade is a representative platform in the field of cloud manufacturing [58]. It can better explain and 


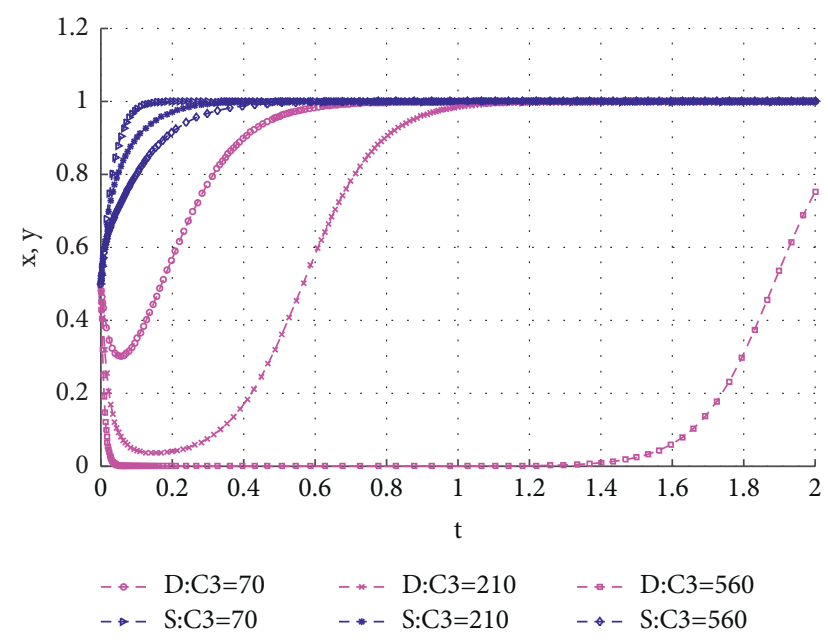

FIGURE 6: The evolutionary result of additional loss changes in opportunistic behavior.

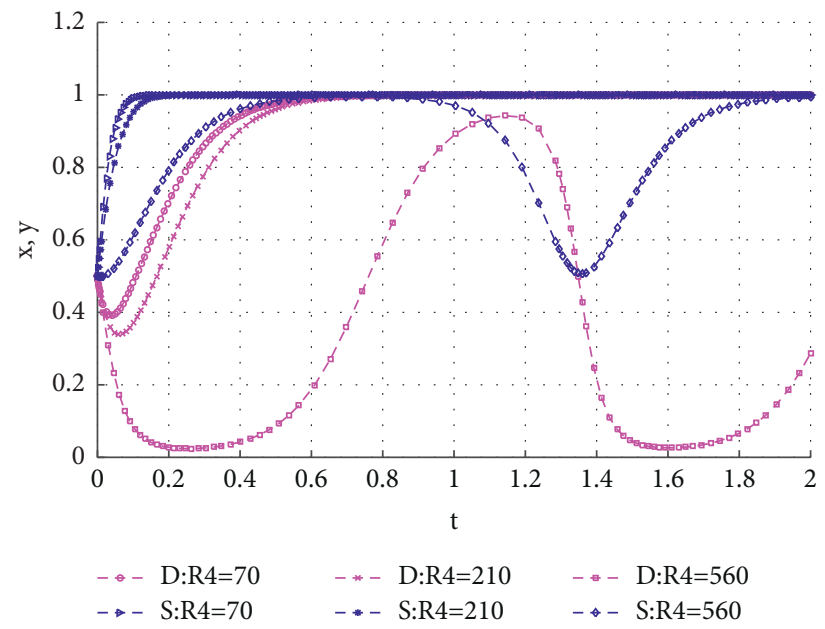

FIgURE 7: The evolutionary result of the change in the extra income of opportunistic behavior.

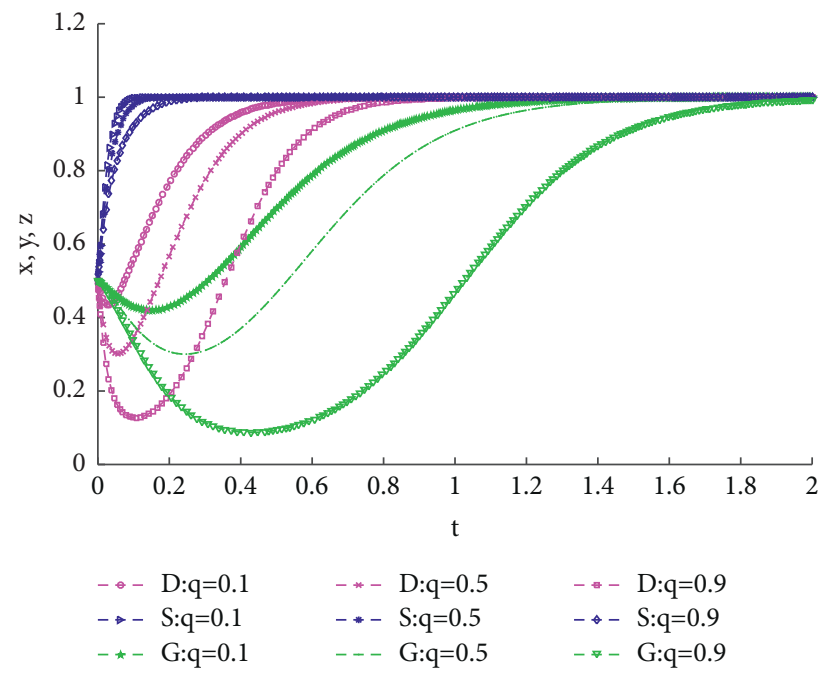

FIGURE 8: The evolutionary result of the historical changes in the interaction between the two parties of the service transaction. 
study the trust relationship between enterprises, which is conducive to the development of cloud manufacturing.

6.1. Synergy between Service Entities. Each service entity in the service composition manufacturing task must provide different resources and capabilities depending on the task. When multiple resources must be combined, the service process may be hampered by inconsistencies in resource integration and sharing, as well as disparities in management methods and operation modes. In the CASICloud, there are many kinds of capability services in the cloud manufacturing environment, such as industrial services, public services, financial services, and security services, when multiple services are required to be combined, because each service enterprise is within different management scope; if there is no better coordination and unified management, the service process will be delayed and even the service quality will be affected. As a result, the greater the degree of synergy and closer the relationship between service entities, the higher the service quality and service process can be guaranteed, increasing the service demander's trust in the service provider. If the synergy between the service entities is not good, it will not only affect the service process but also indirectly damage the reputation of the cloud manufacturing platform. Only by fully grasping the opportunity of collaborative development; effectively improving the order of mutual supplement, cooperation, and role of internal innovation elements; making full use of idle resources; actively giving full play to the collaborative spillover effect; and realizing benign interaction with other enterprises can enterprises improve their efficiency and ability, and effectively promote the development of cloud manufacturing.

6.2. The Supervision Role of Cloud Manufacturing Platforms. Cloud manufacturing platforms play an important part in the manufacturing service process that cannot be overlooked. Its reward and punishment system can successfully increase corporate trust and foster a positive trust relationship. However, the cloud manufacturing platform must design a reward and punishment system as well as a supervisory mechanism that is in line with the organization to attract more users and encourage the development of cloud manufacturing. First, it can offer enterprise-specific incentive and punishment mechanisms, such as priority ranking, resource assistance, and an exclusive interface for service providers in the CASICloud. It can also provide the service demander with free experience, low prices, operating instruction, and other unique offerings. Second, we should raise public knowledge of opportunistic behavior and unqualified businesses, punish them, or put them on a blacklist, depending on the severity of the violation. Finally, the margin system might be applied in service transactions. If an enterprise fails to keep a contract, not only will the cost skyrocket but a legal process will also be initiated. Access to cloud manufacturing platforms will improve service efficiency over time, and enterprises will become increasingly reliant on and trusting of the cloud manufacturing platform.
6.3. The Difference between Opportunistic Behavior and the Importance of Interactive Historical Factors. Because of the various types of resources available, the service provider is very likely to engage in opportunistic behavior during the service composition process. Although the majority of explicit opportunistic behavior is reflected in hardware resources, the service demander can be screened in a variety of ways. Implicit opportunistic behaviors are usually manifested in highly customized and difficult-to-standardize soft resources like experience and ability. Because of its vagueness and implicit character, the service demander is unable to supervise and control the service provider's opportunistic behavior through a formal contract. Therefore, only improving the contract control mechanism cannot inhibit the implicit opportunistic behavior of service providers.

On the contrary, relying solely on the contract control mechanism to strengthen it can easily lead to mistrust and suspicion between the parties. It is conducive for long-term cooperation and win-win cooperation to limit the occurrence of explicit and implicit opportunistic behavior through the quality of interactive history. In essence, human society is made up of individuals who form a network of relationships based on trust and cooperation. The trust relationship develops over time as two people interact with each other. Because there are so many different kinds of services in the CASICloud, and users are not always good at what they do, and there is no standard for the services they get, service enterprises may have a fluke mentality, resulting in different benefits that different users can get from the same resources or services. The service demander will have its own QoS evaluation for cloud manufacturing services that have been interacted with. When examining the legitimacy of QoS assessments after other service demanders engage with a cloud manufacturing service, the service demander is more likely to believe in their interactive experience. Service demanders can fully pick trustworthy cloud manufacturing services and restrict opportunistic behavior in cloud manufacturing by using their history of interactions and QoS evaluation of other service demanders.

6.4. The Concrete Manifestation of the Subjective Perception of the Game Party in Cloud Manufacturing. The subjective will be particularly powerful in cloud manufacturing, due to each game player's limited rationality, and decision-making under uncertainty will be more in line with the prospect theory. When presented with the additional perceived benefits that trust may offer, enterprises exercise caution to ensure that their gains are maximized. The service provider will not hesitate to choose the latter, given the additional benefits that the platform may bring after the end of the service and the determined rewards when it can engage in an opportunistic activity. Even if the nondeterministic return is substantial, we prefer deterministic returns. Because enterprises are unclear of the platform's return and whether it is beneficial to their growth in cloud manufacturing, when service providers are fearful of being penalized for taking advantage of opportunities, they will take risks. There's a good chance their dangerous behavior will go unnoticed. For 
example, the knowledge resources are heterogeneous in the CASICloud knowledge service transaction. Furthermore, some services are based on experience and ability, and the service demander lacks evaluation criteria, causing the service provider to take risks.

\section{Conclusions, Suggestions, and Deficiencies}

7.1. Conclusions. From the perspective of service composition, this paper introduces the prospect theory into the evolutionary game model to better describe the preferences and psychological factors of each game party under bounded rationality. We fully consider the impact of synergy among multi-service entities, platform reward and punishment policies, opportunistic behavior, history of interactions, and other factors on the trust relationship between enterprises, analyze the trust game in cloud manufacturing, and establish an evolutionary game model to make the model conform to the actual situation. Through comparative analysis, the following conclusions are drawn:

(1) The better the degree of synergy between the service entities, the more trustworthy they are. A good collaborative relationship between the service entities will improve the efficiency and quality of services, thus increasing the trust of the service demander.

(2) The relevant reward and punishment policies of the cloud manufacturing platform can indirectly guide service providers to adopt trustworthy behaviors, increase the trust of service demanders, and promote the formation of trust relationships in service transactions.

(3) In the cloud manufacturing service composition, due to many types of services and users being unfamiliar with services, service providers may adopt opportunistic behavior. The distinction between explicit and implicit opportunistic behavior of service providers has a critical relevance. Implicit opportunistic behavior has a high chance. The service demander continues to trust the service provider because it is implicit, allowing the transaction to proceed. When the service provider engages in explicit opportunistic behavior, the service demander will lose faith in them until they are entirely trustworthy. A positive interaction history between cloud enterprises can reduce service providers' opportunistic conduct, boost enterprise trust, and facilitate the formation of trust relationships.

7.2. Suggestions. Based on the foregoing conclusions, an indepth investigation of the aerospace cloud network, and a typical cloud manufacturing platform, the following suggestions are meant to improve enterprise confidence in the cloud manufacturing environment and promote successful cloud manufacturing development.

(1) Relevant interaction and exchange mechanisms can be established between cloud manufacturing service entities through the platform. Good communication and exchanges between entities are the basis and guarantee for the smooth progress of all activities, which not only deepen the enthusiasm for interaction and synergy between entities but also promote the orderly flow and sharing of various resource elements. To ensure that all entities are "profitable," establish an acceptable cooperative benefit-sharing mechanism, and ensure that all service entities adhere to the idea of "more effort, more payment" to contribute to the fulfillment of services.

(2) The cloud manufacturing platform should formulate applicable policies and methods in a progressive and focused manner. Consider the preferences of the various entities on the platform before completing the transaction, and implement a suitable and user-satisfied two-way incentive mechanism that can not only increase the enthusiasm of both parties in the service transaction but also ensure that the company has the ability and integrity to complete the transaction. The monitoring mechanism can be used in the transaction process to achieve unified intelligent detection, supervision, and administration of the entire manufacturing equipment process via the Internet of Things, so that enterprises can understand the manufacturing process anytime and ensure product quality in real time. After the transaction is completed, the demand-oriented mechanism can be adapted to provide some valueadded services to enterprises with good performance to meet their certain needs and increase the stickiness and loyalty of enterprises to the platform.

(3) To prevent the emergence of opportunistic behaviors of service entities and optimize the interests of all parties, cloud manufacturing enterprises should trade or cooperate in good faith and can establish contracts based on contractual relationships. All enterprises using the cloud manufacturing platform should sign up for the social credit linking system as well. If an enterprise has negative behavior, it will be regulated from the standpoints of government, finance, business, and others to strengthen the enterprise's self-discipline consciousness, establish a favorable trading environment, and support the growth of cloud manufacturing.

7.3. Deficiencies. The deficiencies of this paper are: (1) For the generation of opportunistic behavior, only the service provider is considered; other participants may also exhibit opportunistic behavior affecting the trust relationship between enterprises. (2) Data within the simulation is a part of this paper and cannot simulate the real operation of cloud manufacturing. In order to conduct future analyses, indepth research on cloud manufacturing enterprises and cloud platforms will be conducted.

\section{Data Availability}

The data used to support the findings of this study are included within the article. 


\section{Conflicts of Interest}

The authors declare that there are no conflicts of interest.

\section{Acknowledgments}

This research was supported by the National Natural Science Foundation of China (Nos. 71804035 and 71672050), Philosophy and Social Science Youth Project in Heilongjiang Province (No. 20GLC203), and Fundamental Research Foundation for Universities of Heilongjiang Province (No. LGYC2018JC058).

\section{References}

[1] D. Li, C. Li, and R. Gu, "Evolutionary game analysis of promoting industrial internet platforms to empower manufacturing SMEs through value cocreation cooperation," Discrete Dynamics in Nature and Society, vol. 2021, Article ID 4706719, 14 pages, 2021.

[2] B. H. Li, L. Zhang, S. L. Wang et al., "Cloud manufacturing: a new service-oriented networked manufacturing model," Computer Integrated Manufacturing Systems, vol. 16, no. 1, pp. 1-7, 2010.

[3] L. Ren, L. Zhang, Y. B. Zhang, F. Tao, and Y. L. Luo, "Resource virtualization in cloud manufacturing [J]," Computer Integrated Manufacturing Systems, vol. 17, no. 3, pp. 511-518, 2011.

[4] Y. F. Zhang, G. Zhang, Y. Liu, and D. Hu, "Research on services encapsulation and virtualization access model of machine for cloud manufacturing," Journal of Intelligent Manufacturing, vol. 28, no. 4, pp. 1109-1123, 2017.

[5] B. H. Li, L. Zhang, and X. D. Chai, "Introduction to cloud manufacturing," Zte Communications, vol. 8, no. 4, pp. 6-9, 2010.

[6] F. Tao, Y. Cheng, L. Zhang, and A. Y. C. Nee, "Advanced manufacturing systems: socialization characteristics and trends," Journal of Intelligent Manufacturing, vol. 28, no. 5, pp. 1079-1094, 2017.

[7] J. Li, F. Tao, Y. Cheng, and L. J. Zhao, "Big data in product lifecycle management," International Journal of Advanced Manufacturing Technology, vol. 81, no. 1/2/3/4, pp. 667-684, 2015.

[8] Q. Wang, C. C. Liu, and B. R. Zhou, "Trusted transaction method of manufacturing services based on blockchain [J]," Computer Integrated Manufacturing Systems, vol. 25, no. 12, pp. 3247-3257, 2019.

[9] Y. Feng and B. Q. Huang, "Hierarchical and configurable trust evaluation model of cloud manufacturing services," Computer Integrated Manufacturing Systems, vol. 23, no. 10, pp. 22912303, 2017.

[10] Y. L. Chen, D. Huang, Y. Y. Zhang, and J. P. Zhao, "Evaluation and selection for knowledge resources in cloud manufacturing environment," Journal of Northeastern University, vol. 39, no. 8, pp. 1169-1174, 2018.

[11] X. Du, S. Ge, N. Wang, and Z. Yang, "Personalized product service scheme recommendation based on trust and cloud model," IEEE Access, vol. 8, no. 99, p. 1, 2020.

[12] J. Liu and Y. Chen, "A personalized clustering-based and reliable trust-aware QoS prediction approach for cloud service recommendation in cloud manufacturing," Knowledge-Based Systems, vol. 174, no. 15, pp. 43-56, 2019.
[13] X. X. Yang, S. L. Wang, B. Yang, C. Ma, and L. Kang, “A service satisfaction-based trust evaluation model for cloud manufacturing," International Journal of Computer Integrated Manufacturing, vol. 32, no. 4/6, pp. 1-13, 2019.

[14] Y. X. Li, X. F. Yao, and M. Liu, "Cloud manufacturing service composition optimization based on reliability and credibility analysis," Computer Integrated Manufacturing Systems, vol. 27, no. 6, pp. 1-33, 2021.

[15] J. Wu, S. Guo, H. Huang, W. Liu, and Y. Xiang, "Information and communications technologies for sustainable development goals: state-of-the-art, needs and perspectives," IEEE Communications Surveys \& Tutorials, vol. 20, no. 3, pp. 2389-2406, 2018.

[16] C. Yang, B. H. Li, X. D. Chai, F. G. Zhang, T. Y. Lin, and Y. B. Zhang, "Cloud manufacturing oriented cloud simulation supporting framework and its application process model," Computer Integrated Manufacturing Systems, vol. 18, no. 7, pp. 1444-1452, 2012.

[17] H. M. Tang and G. Guo, "Virtualization descriptions and integrated intelligent service model of cloud manufacturing resources," China Mechanical Engineering, vol. 27, no. 16, pp. 2172-2178, 2016.

[18] J. Wu and S. B. Li, "The hardware resource virtual encapsulation in cloud manufacturing," Machinery Design \& Manufacture, no. 7, pp. 112-115, 2014.

[19] J. G. Deng, Y. L. Zhao, H. Q. Yuan, and M. Tao, "Multiobjective constraint grid task collaborative scheduling model," Journal of Information and Computational Science, vol. 9, no. 14, pp. 4055-4064, 2012.

[20] Y. Kong, M. Zhang, and D. Ye, "A belief propagation-based method for task allocation in open and dynamic cloud environments," Knowledge-Based Systems, vol. 32, no. 9, pp. 100-115, 2018.

[21] B. F. Bao, Y. Yang, L. T. Li, F. Li, A. J. Liu, and N. Liu, "Multiobjective optimization for task allocation of product customization collaborative development," Computer Integrated Manufacturing Systems, vol. 20, no. 4, pp. 739-746, 2014.

[22] Y. F. Dong and G. Guo, "Evaluation and selection approach for cloud manufacturing service based on template and global trust degree," Computer Integrated Manufacturing Systems, vol. 20, no. 1, pp. 207-214, 2014.

[23] Y. L. Zhang, J. F. Tu, and W. D. Xie, "Cloud manufacturing resource evaluation based on fuzzy hierarchical analysis," Machinery, vol. 53, no. 6, pp. 49-52, 2015.

[24] K. B. Jiang, W. X. Ji, and C. Y. Zhang, "Research on cloud manufacturing service optimization method based on enterprise intimacy," Modern Manufacturing Engineering, no. 3, pp. 39-46+141, 2020.

[25] Y. Yu, L. F. Sun, C. H. Ren, and M. Han, "Bilateral matching model of business resources for multi-service value chain," Computer Integrated Manufacturing Systems, vol. 27, no. 5, pp. 1397-1409, 2021.

[26] X. Yang, Z. X. Zeng, and J. F. Ma, "Research on the present situation and future direction of cloud manufacturing," Journal of Hebei University of Technology(Social Sciences Edition), vol. 9, no. 4, pp. 22-28, 2017.

[27] F. Tao, Y. Laili, L. Xu, and L. Zhang, "FC-PACO-RM: a parallel method for service composition optimal-selection in cloud manufacturing system," IEEE Transactions on Industrial Informatics, vol. 9, no. 4, pp. 2023-2033, 2013.

[28] B. Huang, C. Li, and F. Tao, "A chaos control optimal algorithm for QoS-based service composition selection in cloud manufacturing system," Enterprise Information Systems, vol. 8, no. 4, pp. 445-463, 2014. 
[29] Y. Que, W. Zhong, H. L. Chen, X. N. Chen, and X. Ji, "Improved adaptive immune genetic algorithm for optimal QoS-aware service composition selection in cloud manufacturing," International Journal of Advanced Manufacturing Technology, vol. 96, no. 9-12, pp. 4455-4465, 2018.

[30] B. Liu and Z. L. Zhang, "QoS-aware service composition for cloud manufacturing based on the optimal construction of synergistic elementary service groups," International Journal of Advanced Manufacturing Technology, vol. 88, no. 9-12, pp. 2757-2771, 2017.

[31] Z. Wang, S. Wang, B. Yang, Y. Wang, and R. Chen, "A novel hybrid algorithm for large-scale composition optimization problems in cloud manufacturing," International Journal of Computer Integrated Manufacturing, vol. 34, no. 9, pp. 898919, 2021.

[32] R. A. Fisher, "The genetical theory of natural selection," in Biological Reviewsvol. 126, no. 3181, OUP Oxford, Oxford, UK, 1930.

[33] F. Zhang and J. F. Cai, "Research on evolutionary game of military-civil cooperation innovation: based on the support of government," Operations Research and Management Science, vol. 30, no. 2, pp. 8-15, 2021.

[34] Z. He, Z. Z. Zhang, and B. Li, "Evolutionary game model of knowledge transfer incentive in cloud manufacturing supply chains," China Mechanical Engineering, vol. 31, no. 6, pp. 695-705, 2020.

[35] M. Li, X. Jin, C. Guo, J. Liu, G. Cui, and T. Qiu, "RIMNet: recommendation Incentive Mechanism based on evolutionary game dynamics in peer-to-peer service networks," Knowledge-Based Systems, vol. 166, no. 15, pp. 156-169, 2019.

[36] T. Wang, C. Li, Y. Yuan, J. Liu, and I. B. Adeleke, "An evolutionary game approach for manufacturing service allocation management in cloud manufacturing," Computers \& Industrial Engineering, vol. 133, pp. 231-240, 2019.

[37] E. S. Qi, T. B. Li, L. Liu, Y. X. Zhao, and G. T. Qiao, “The evolutionary game analysis of the sharing of manufacturing resource in the environment of cloud manufacturing," $O p$ erations Research and Management Science, vol. 26, no. 2, pp. 25-34, 2017.

[38] C. A. Xu and F. Li, "Game model analysis of symmetrical enterprise's manufacturing resources sharing under environment of clouding manufacturing," Application Research of Computers, vol. 36, no. 11, pp. 1-9, 2019.

[39] P. Lou, L. Yuan, J. Hu, J. Yan, and J. Fu, "A comprehensive assessment approach to evaluate the trustworthiness of manufacturing services in cloud manufacturing environment," IEEE Access, vol. 6, Article ID 30819, 2018.

[40] D. Yang, Q. Liu, J. Li, and Y. Jia, "Multi-objective optimization of service selection and scheduling in cloud manufacturing considering environmental sustainability," Sustainability, vol. 12, no. 18, p. 7733, 2020.

[41] Y. J. Hu, L. Z. Wu, L. Zhang, Y. Wang, X. F. Chang, and C. Shi, "Review on theory and method of cloud manufacturing service evaluation," Computer Integrated Manufacturing Systems, vol. 23, no. 3, pp. 640-649, 2017.

[42] K. Yan, Y. Cheng, and F. Tao, "A trust evaluation model towards cloud manufacturing," International Journal of Advanced Manufacturing Technology, vol. 84, no. 1-4, pp. 1-14, 2016.

[43] Y. X. Wu, G. Z. Jia, and Y. Cheng, "Cloud manufacturing service composition and optimal selection with sustainability considerations: a multi-objective integer bi-level multi- follower programming approach," International Journal of Production Research, vol. 58, no. 19/20, pp. 6024-6042, 2020.

[44] X. Q. Gao, B. B. Zhu, and J. F. Du, "Servitization description and virtualization encapsulation of manufacturing resources under cloud mode," Manufacturing Automation, vol. 39, no. 10, pp. 140-145, 2017.

[45] J. H. Yang, H. J. Gao, and H. W. Yin, “The relational governance and opportunism behavior in horizontal alliances among logistics service providers," Soft Science, vol. 31, no. 1, pp. 124-129, 2017.

[46] Z. F. Su, "The impact of multidimensional proximity on cooperative innovation," Studies in Science of Science, vol. 37, no. 1, pp. 112-120+164, 2019.

[47] J. H. Li, L. N. Mao, and J. X. Wang, "Technological knowledge integration, opportunistic behavior and innovation performance in complex product," Studies in Science of Science, vol. 38, no. 11, pp. 2097-2112, 2020.

[48] K. A. Tversky, "Prospect theory: an analysis of decision under risk," Econometrica, vol. 47, no. 2, pp. 263-291, 1979.

[49] D. Q. Tan and H. Xu, "Evolutionary equilibrium analysis of mass emergency derived from environmental pollution based on prospect theory," Operations Research and Management Science, vol. 29, no. 5, pp. 161-170, 2020.

[50] B. Tobias, J. Reiner, M. Natter, and B. Skierab, "Prospect theory in a dynamic game: theory and evidence from online pay-per-bid auctions," Journal of Economic Behavior \& Organization, vol. 164, pp. 215-234, 2019.

[51] R. L. Gao, Y. N. Zhou, and J. C. Liu, "Adverse selection of investors in PPP projects based on prospect theory," Chinese Journal of Management Science, vol. 29, no. 1, pp. 36-46, 2021.

[52] J. Z. Xu and Y. Y. Xu, "Low-carbon technology innovation diffusion under environmental regulation-_evolutionary game analysis based on prospect theory," Systems Engineering, vol. 33, no. 2, pp. 118-125, 2015.

[53] G. Heutel, "Prospect theory and energy efficiency," Journal of Environmental Economics and Management, vol. 96, pp. 236-254, 2019.

[54] L. Wang and Y. M. Wang, "Study on the emergency decision method of dynamic reference point based on prospect theory," Chinese Journal of Management Science, vol. 21, no. s1, pp. 132-140, 2013.

[55] X. Q. Wen, Logistics-involved QoS-Aware Service Composition in Cloud Manufacturing with Deep Reinforcement Learning, Chang'an University, Xi'an, China, 2020.

[56] A. Tversky and D. Kahneman, "Advances in prospect theory: cumulative representation of uncertainty," Journal of Risk and Uncertainty, vol. 5, no. 4, pp. 297-323, 1992.

[57] W. L. Chen, C. R. Lin, J. Q. Li, Z. L. Yang, and Y. Lin, "Research on the optimization of patent agency services from perspective of prospect theory," Operations Research and Management Science, vol. 28, no. 12, pp. 14-24, 2019.

[58] B. Sun and X. Chai, "Aerospace cloud network: industrial internet platform helps enterprises' digitalization and intelligent transformation," China Economic Weekly, no. 1, pp. 58-59, 2019. 